\title{
Statin-associated necrotizing autoimmune myopathy with concurrent myasthenia gravis
}

emma frasson $^{1}$, marco simonetto ${ }^{1}$, Laura Bertolasi ${ }^{2}$, giorgio caneve ${ }^{1}$, $_{\text {. }}$ istina vilotti ${ }^{1}$, giampietro ruzza $^{1}$, anna perelli ${ }^{1}$, maria grazia piccinno $^{1}$, and salvatore monaco ${ }^{2}$

${ }^{1}$ Affiliation not available

${ }^{2}$ Integrated University Hospital of Verona

October 3, 2020

\begin{abstract}
A patient developed necrotizing autoimmune myopathy and myasthenia gravis after statin exposure. Clinicians should be alerted to possible concurrent autoimmune neuromuscular disorders to discontinue the drug and promptly begin appropriate treatment,
\end{abstract}

\section{Hosted file}

Frasson et.pdf available at https://authorea.com/users/363989/articles/484582-statinassociated-necrotizing-autoimmune-myopathy-with-concurrent-myasthenia-gravis 

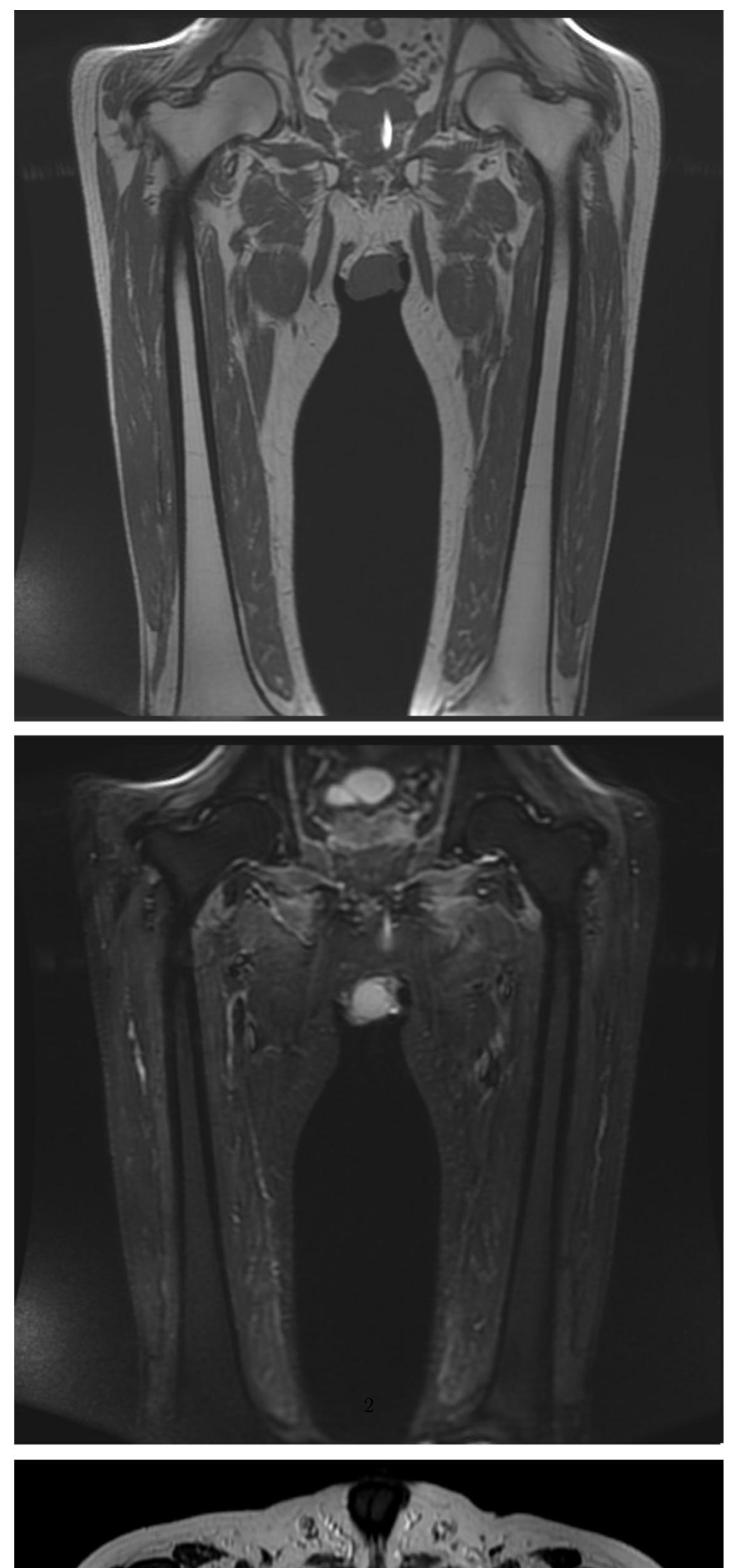

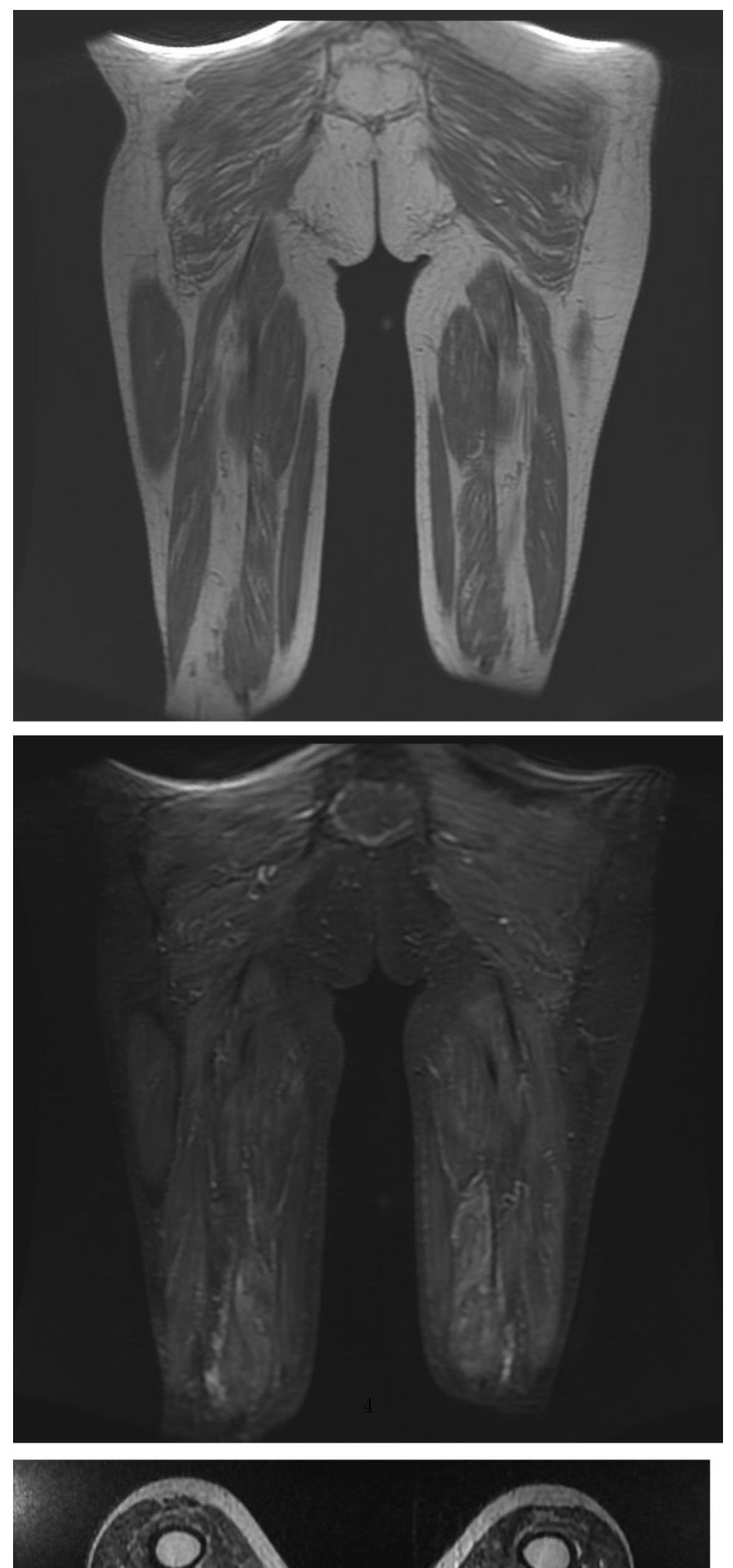